\title{
Limited Self-Control, Obesity and the Loss of Happiness
}

\author{
Alois Stutzer and Armando N. Meier ${ }^{*}$, University of Basel
}

Abstract: Is obesity the consequence of an optimally chosen lifestyle or do people consume too much relative to their long-term preferences? The latter perspective accepts that people might face self-control problems when exposed to the immediate gratification from food. We exploit unique survey data for Switzerland in multinomial logit and ordered probit regressions to study i) the covariates of obesity including indicators of self-control, and ii) the consequences of obesity on the subjective well-being of people with limited willpower. Our main finding is that obesity decreases the well-being of individuals who report having limited self-control, but not otherwise.

JEL classifications: D12, D91, I12, I31

Keywords: obesity, revealed preference, self-control problem, subjective well-being

\footnotetext{
* Address: Faculty of Business and Economics, University of Basel, Peter Merian-Weg 6, 4002 Basel, Switzerland, email: alois.stutzer@unibas.ch, armando.meier@unibas.ch Revised version for Health Economics. We are grateful to Christine Benesch, Fabrice Etilé, Bruno Frey, Alexander Grob, Simon Lüchinger, Stephan Meier, Susanne Neckermann, Reto Odermatt, Andrew Oswald, Jürg Sommer, and Wolfgang Stroebe for helpful remarks and the Swiss Federal Statistical Office for providing the Swiss Health Survey as a data source for this study.
} 


\section{Introduction}

According to the WHO, obesity is one of the most pressing health issues today (World Health Organization 2013). Overweight and obesity ${ }^{1}$ cause health problems such as diabetes and heart disease. A large amount of recent literature deals with obesity as a social health issue (see, e.g., Etilé 2007; Smith 2012; Swinburn et al. 2011; Tomer 2011), as well as a driver of mortality (see, e.g., Flegal et al. 2005; Flegal et al. 2013). The question arises whether contemporary weight gain and its health consequences are the result of an optimally chosen lifestyle in response to changes in relative prices, or whether people consume too much with respect to to their long-term preferences. The latter perspective accepts that people might face self-control problems when exposed to the temptation of immediate gratification from food (see, e.g., Offer 2001).

There is abundant literature on the control of eating which emphasizes physiological mechanisms (Blundell and Gillett 2001; Smith 2009). In particular, humans are endowed with a biological weight regulation system that favors weight gain over weight loss in order to reduce any future risk of starvation. While this regulation mechanism was advantageous to human evolutionary development, today it may challenge the individual's conscious control of food intake. As a result, people might consume more food and calories and eat more frequently than they consider good for themselves or than their planned diet prescribes.

In this paper, the possibility of systematic errors in food consumption is considered. We study the potentially adverse welfare consequences of self-control problems using data on reported subjective well-being as an approximation of individual welfare (see, e.g., Frey and Stutzer 2012, Stutzer and Frey 2010). People's behavior is assessed depending on their ex post

\footnotetext{
${ }^{1}$ Overweight and obesity are often defined relative to people's weight to height ratio in metric units, as captured by the body mass index (BMI): $\mathrm{BMI}=\mathrm{kg} / \mathrm{m}^{2}$. Following the $\mathrm{WHO}$, we classify adults with a BMI $\geq 30 \mathrm{~kg} / \mathrm{m}^{2}$ as obese and those with a $\mathrm{BMI} \geq 25 \mathrm{~kg} / \mathrm{m}^{2}$ as overweight.
} 
evaluation of experienced utility. Specifically, we study whether the ex post evaluation systematically varies between groups of people who report different amounts of willpower. We hypothesize that obesity makes people particularly worse off in terms of experienced utility if the increased body mass is due to a self-control problem. However, for people who have no self-control and willpower problems, we do not expect that a BMI above 30 will reduce their evaluation of their subjective well-being.

In our empirical approach, we do not put any restrictions on what the main correlation between subjective well-being and either self-control or body mass is. The key element of our test is the relationship between the former and the interaction of the two latter parameters. Subsequently, there is no contradiction of premises with this approach if big people are jollier. We simply predict that, when comparing the well-being appraisals of obese and normal-weight people, obese people who indicate that they have a self-control problem (limited willpower) judge their overall well-being less favorably than obese people who indicate that they do not have a self-control problem (possess willpower).

We base the empirical analysis on a unique data set combining information on people's weight, height, perceived control over their lives and eating behavior, as well as a multi-item measure of subjective well-being. This data set allows us to: (1) replicate analyses on the covariates of people's BMI; (2) augment the standard socio-economic factors of obesity with two measures for limited self-control; and (3) study the differential effects of obesity on subjective well-being. We find that people who report a lack of willpower as an obstacle to a healthy diet (i) are more likely to be obese, and (ii) have a reduced evaluation of their subjective well-being when they are obese, ceteris paribus.

Our paper relates to two strands of literature. First, there is a debate about the economic causes of the obesity phenomenon, as well as its consequences (see, e.g., Brunello 2009; Cavaco et al. 2014; Cutler et al. 2003; Finkelstein et al. 2005; Grossman and Mocan 2011; 
Smith 2012; Wang et al. 2011). Increased obesity has been explained in terms of energy expenditure and energy intake. Energy expenditure is lower nowadays, because manual labor has been replaced by more sedentary work due to technological changes (Lakdawalla and Philipson 2009). ${ }^{2}$ In addition, looking at relative prices suggests that there has been a decrease in the price of calorie-dense foods and drinks compared to fruit and vegetables, which are less energy-dense (Cawley 2010; Finkelstein et al. 2005). These price reductions were possible due to new technologies in food production, in particular for pre-packaged and prepared food. People have reacted by eating more frequently, eating bigger portions, and spending less time on preparing meals. Additionally, living in the proximity of fast-food restaurants contributes further to the effect of relative price changes (Currie et al. 2009).

Second, there is a growing strand of empirical research that studies whether obese people are less satisfied (e.g. Ball et al. 2004; Katsaiti 2012; McElroy et al. 2004; Needham and Crosnoe 2005). Many of these findings, however, provide only limited insights regarding the role of self-control problems, as the correlations can be due to third variables affecting both eating behavior and subjective well-being, or because low life satisfaction and stress can lead to obesity (Korkeila et al. 1998).

The remainder of the paper is structured as follows. In Section 2, we characterize our data and discuss the methodology. Section 3 presents the results of the empirical analyses. Section 4 offers concluding remarks.

\footnotetext{
${ }^{2}$ However, this trend started long before the obesity epidemic developed. The increase in calories consumed fits the obesity pattern better and is of sufficient magnitude to account for its increased prevalence (Jones Putnam and Allshouse 1999). In the United States in particular, higher snack calories are considered responsible for a higher energy intake for men, and for even higher energy intake for women (Cutler et al. 2003).
} 


\section{Data and Methodology}

\subsection{Data}

Data from the Swiss Health Survey compiled by the Swiss Federal Statistical Office serve as the basis for the empirical analysis. There are two reasons for choosing the specific data set for Switzerland in 2002. First, it offers the unique combination of information about people's body mass, subjective well-being and self-control that is necessary for our approach to test the role of limited self-control in the relationship between obesity and happiness. Second, it includes a representative sample of a western country which is experiencing increased food availability. Between 1992 and 2012, the percentage of obese people in the adult population increased from $5.4 \%$ to $10.3 \%$. It amounted to $7.7 \%$ in 2002 .

We assess people's subjective well-being using the multi-item Bern Questionnaire of Subjective Well-Being (Grob et al. 1991). We use the answers to the corresponding eight questions to construct a discrete subjective well-being measure that ranges from one to six. Variation in self-control between people is measured using a general measure of reported mastery and a specific measure of reported willpower in pursuing a healthy diet.

The Swiss Health Survey includes information about a wide range of other individual characteristics, which we take into account in the empirical analysis. We present descriptive statistics and detailed descriptions of the variables from the questionnaire in the Appendix.

\subsection{Methodology}

We briefly describe how we set up our empirical models to analyze the determinants of (i) body mass and (ii) subjective well-being. 


\section{Estimation approach for body mass}

According to the standard categorization, people's body mass falls into one of four categories: underweight, normal weight, overweight and obesity. Even though these categories follow the metric of the BMI, they are not inherently ordered or necessarily monotonic. For instance, Flegal et al. (2005) show that the excess mortality is a non-monotonic function of categorized BMI. Therefore, underweight and obesity are related but separate phenomena, i.e. obesity is not equivalent to less underweight.

Accordingly, we use multinomial logit regressions to study the covariates of the low and high BMI (Tables 1 and 2). Estimates are based on:

$$
\log \left(\frac{\pi_{i j}}{\pi_{i 1}}\right)=x_{i}^{\prime} \beta_{j}
$$

Where $\pi_{i j}$ is equal to an individual i's probability of being in category $\mathrm{j}$ (e.g., of being obese), and $\pi_{i 1}$ is the base category, in our case normal weight. These probabilities are a function of the individual specific regressor vector $x_{i}$ (which contains distinct regressors denoted by $x_{l}$ ) and category-specific coefficients $\beta_{j}$. The coefficients are estimated using maximum likelihood.

For ease of interpretation, we compute the relative risk ratios for the three categories underweight, overweight and obesity, denoted by $\mathrm{j}$, relative to normal weight as follows:

$$
R R R_{j}=\frac{\exp \left(x^{\prime} \beta_{j}+\Delta x_{l} \beta_{j l}\right)}{\exp \left(x^{\prime} \beta_{j}\right)}=\exp \left(\Delta x_{l} \beta_{j l}\right)
$$

Thus, the relative risk changes by a factor of $R R R_{j}=\exp \left(\beta_{j l}\right)$ compared to the baseline category "normal weight" if a specific regressor $x_{l}$ changes by $\Delta x_{l}=1$, holding the other regressors constant. Z-values reflect whether the estimated relative risk ratios are statistically different from one. For instance, the relative risk of being underweight rather than having a 
normal weight is higher for women than for men by a factor 3.56, ceteris paribus (see Table 1).

\section{Estimation approach for subjective well-being}

The dependent variable of reported subjective well-being is an ordinal measure. Accordingly, we model individual probabilities of being in a particular well-being category $\pi_{i j}$ with an ordered probit model (see also, e.g., Di Tella and MacCulloch 2006):

$$
\pi_{i j}\left(x_{i} ; \theta\right)=\Phi\left(\kappa_{j}-x_{i}^{\prime} \beta\right)-\Phi\left(\kappa_{j-1}-x_{i}^{\prime} \beta\right)
$$

The parameters $\theta=\left(\kappa_{1}, \ldots, \kappa_{j-1}, \beta^{\prime}\right)^{\prime}$ are estimated using maximum likelihood. $\Phi$ denotes the normal cumulative density function, and $\kappa_{j}$ are threshold parameters that are estimated from the data. The individual specific regressors are contained in the vector $x_{i}$ and the coefficient vector is denoted by $\beta$.

To simplify interpretation, we present probability effects $\Delta \pi_{j}(\bar{x} ; \theta)$ of a change from zero to one in regressor $x_{l}$ for the highest well-being category, evaluated at the average value of the other regressors (Tables 3 and 4):

$$
\Delta \pi_{j}(\bar{x} ; \theta)=P\left(y=j \mid \bar{x}+\Delta x_{l} ; \theta\right)-P(y=j \mid \bar{x} ; \theta)
$$

We choose the vector of regressors $x$ in accordance with the literature on the determinants of obesity, on the one hand, and on the determinants of subjective well-being, on the other hand (see, e.g., Frey and Stutzer 2000; Katsaiti 2012; Wang and Beydoun 2007). In order to provide a complete picture of the regularities in our data, we estimate our specifications with a full set of controls (age categories, sex, level of education, marital status, household composition, citizenship status, main life circumstances, and income), as well as with a 
minimal set of exogenous controls (age categories and sex). ${ }^{3}$ The latter specification serves as a check for potential endogeneity issues with control variables that might bias the main correlations of interest.

Finally, the exogeneity of the self-control and the obesity measures is not guaranteed. For instance, unhappy people might resort to eating, or individuals who experience reduced wellbeing as a result of obesity might explain their conditions in terms of limited self-control. In both cases, an instrumental variable approach would help to overcome the potential endogeneity problem. However, we lack appropriate instruments for both variables in our cross-section survey. Thus, we document important associations rather than causal relationships. Nonetheless, we present a series of tests that might provide a better overall picture of the phenomenon (see Section 3.4).

\section{Results}

We present three sets of results. First, we study the covariates of body mass in a baseline estimation including standard demographic and socio-economic factors. Second, we extend the empirical model to include indicators of limited willpower. Third, we relate people's body mass to their subjective well-being. We test whether there are differential effects for people with full and limited willpower as hypothesized above.

\footnotetext{
${ }^{3}$ The corresponding results for Tables 2 and 4 with only age categories and sex as control variables can be found in the online Appendix. For a discussion of the potential endogeneity of obesity and other covariates in happiness regressions, as well as for a corresponding analysis based on panel data, we refer the reader to Katsaiti (2012).
} 


\subsection{Covariates of Obesity}

Table 1 shows relative risk ratios from a multinomial logit regression, whereby the base outcome is normal weight. While we have to take all possible outcomes of BMI jointly into account in the statistical analysis, we focus on obesity when discussing the results.

\section{[Table 1 about here]}

The covariates of obesity show a pattern that is akin to that in a prominent study for the United States by Chou et al. (2004). As in the case of the United States, people with a higher level of education than mandatory schooling have a statistically significantly smaller probability of being obese. In the same vein, the probability of an individual being obese decreases with higher income (see also Wang and Beydoun 2007). These findings are in line with the notion of better-educated people living a healthier life. They are also consistent with a higher expected labor-market penalty for obesity with these groups. Similar to the United States, widowed people are more likely to be obese than married people, which may reflect grieving. The probability of a woman being obese is markedly lower than for a man, ceteris paribus. This observation does not correspond to the gender difference in obesity in the United States, where men have a slightly lower probability of being obese (Chou et al. 2004).

\subsection{Limited Self-Control and Obesity}

Table 2 presents further results for the determinants of obesity. In addition to the demographic and socio-economic factors included in the baseline estimation, we take people's concerns about i) their health, ii) their nutrition, and iii) their willpower into account. In estimation A, the importance individuals attribute to health is considered. We find that people who report that health is not a relevant issue for them are statistically significantly more likely to be obese than people who report that health is either relevant or very important for them. Here, the relative risk ratio indicates a 1.51 times larger probability than for people in the reference 
group. The finding in estimation B is consistent with this. People who care about their diet are less likely to be obese, with a risk ratio of 0.81 relative to people who do not care.

[Table 2 about here]

Estimation $\mathrm{C}$ presents correlations between reported obstacles to a healthy diet and body mass. Here, the interpretation of the relative risk ratios needs caution. Social desirability and self-justification might well distort some people's self-reports and thus the measured correlations. However, in estimation $\mathrm{C}$, all the survey items are jointly included and not all items are equally attractive in justifying overweight or obesity. Our results indicate that six obstacles to a healthy diet are statistically significantly correlated with obesity: not enough choice in shops, the relative cost of healthy food, not enough support from others, strong preference for good food, a preference for large portions of food, and lack of willpower. While the high relative risk ratio of 1.85 for obesity in the case of a strong preference for good food, may well capture taste, it may also reflect an easy excuse for being overweight or obese. Such an alternative interpretation seems less plausible for the partial correlation with lack of willpower. One may argue that a lack of willpower increases the probability of being obese, the relative risk ratio amounting to 1.40 .

Estimation D studies the differential obesity risk for a general indicator of perceived control. We find no statistically different probability between the group with full self-control and that with limited self-control. In conlusion, the relative risk ratio with domain-specific reports of willpower indicates some bounded rationality in food consumption, while the relative risk ratio with the general indicator does not.

\subsection{Obesity and Subjective Well-Being}

The Swiss Health Survey provides sufficient information about individual characteristics to specify a micro econometric well-being function that is similar to those usually applied when 
testing economic issues. Table A.2 in the Appendix presents the results for such a specification, including all the control variables and covering the full sample. These results confirm previous findings in the literature on the correlates of happiness.

People's judgments of their subjective well-being allow for a nuanced evaluation of high body weight. According to the basic hypothesis, we expect obesity to negatively affect the subjective well-being of people with limited willpower. For these people, obesity is not the outcome of rational food consumption, but rather of time-inconsistent behavior. In Table 3, we present results for two different specifications. Specification A includes people's body mass, split into four categories, as well as control variables for people's age (in categories) and sex. This specification assures that no choice variable other than body mass picks up any potential negative consequence of obesity on well-being. Specification B includes a large set of covariates of subjective well-being.

[Table 3 about here]

In both equations with the full sample, obesity correlates negatively with subjective wellbeing. However, the partial correlation is not statistically significant in specification B. Moreover, the partial correlations are not yet a test of the theoretical prediction. We hypothesize that a very high BMI affects well-being negatively if it is the result of limited self-control, but not (or much less) otherwise. Therefore, we estimate the partial correlation between obesity and subjective well-being separately for people with full and limited selfcontrol. Both indicators of self-control are applied: mastery and domain-specific willpower. Table A.3 in the Appendix shows the number of observations for each combination of body mass and self-control. In the least populated cell (full mastery x underweight), there are 109 observations. This is about a fifth of the underweight people in the sample. The distribution of characteristics thus allows an implementation of the proposed empirical test. With two specifications each, we depict the corresponding results from eight estimations in Table 3. 
Consistent with the basic hypothesis, obesity relates to lower subjective well-being when people have limited self-control, but we find no statistically significant effect for the sample of people classified as having full self-control. For both indicators as well as for both specifications A and B, the obesity coefficients are statistically significantly different when applying a simple t-Test. The same holds true for the corresponding probability effects, except for the general indicator of self-control in specification A. The negative effect of obesity is largest for the sample of people who report a lack of willpower as being an obstacle to a healthy diet, when controlling for age categories and sex (specification A). Here, the probability of reporting high subjective well-being is 3.3 percentage points lower for people who are obese than for those of normal weight (both reporting low self-control). To put the difference into perspective, the probability that a person in this subsample with average values for the regressors reports a well-being rank of 6 is 8.6 percent. Taken together, the pieces of evidence indicate that we can only understand the phenomenon of obesity when we go beyond revealed preference and the assumption of unlimited consumer sovereignty and also consider limited self-control.

\subsection{Robustness analysis and discussion}

Our analyses invite at least two considerations regarding the interpretation of the findings, i.e. with regard to people's capacity for self-regulation as well as reverse causality. As far as possible, we address these issues empirically and conduct robustness tests for our main results (Table 3).

The first issue has to do with the nature of limited self-control. Opportunities with low immediate marginal costs, but high marginal benefits abound. The question arises as to whether people with a self-control problem make myopic decisions when faced with all or most of these opportunities, or whether they are able to withstand some challenges to selfcontrol, but find it too difficult to withstand all of them. The latter view supports the idea that 
people may have a limited capacity for self-regulation. Resisting one temptation may result in poorer regulation of another desire for immediate gratification, or vice versa (Muraven et al. 1998).

In our case, it could well be that obese people with low self-control are unhappy owing to activities other than eating which also require their self-control. The idea that self-control resembles a muscle might be particularly relevant in understanding the interplay between obesity and smoking (Baum 2009; Baum and Chou 2011; Gruber and Frakes 2006). People who work at controlling their eating habits might stop trying to give up smoking, and vice versa. Alternatively, cigarettes potentially function as appetite-suppressants and thus might support their dietary self-control efforts. Therefore, when testing for an interaction of selfcontrol and obesity, we also include information about whether somebody is a smoker or nonsmoker. For the main specification B, with separate estimations depending on the level of self-control, we find virtually identical marginal effects as before. For people with limited self-control, the marginal effect of obesity is -0.026 ( -0.026 before). For people with full selfcontrol, the marginal effect of obesity is 0.005 ( 0.005 before). The main result is thus robust to the inclusion of the closest substitute to yielding to the temptation to overconsume.

The second issue concerns causality. To what extent do the consequences of obesity due to limited willpower reduce subjective well-being and to what extent does the experience of reduced well-being lead to stress-/frustration-related eating and obesity? This is a valid concern, even though we do not interpret the correlation between obesity and subjective wellbeing as such, but rather the differential effect of obesity for people with full and limited selfcontrol. The data set at hand captures whether a person turns to eating when stressed. We include the responses to this item as additional control variables in the estimation equation explaining subjective well-being (specification B in Table 3). The test is now whether obesity still reduces subjective well-being more in the case of limited willpower than in the case of 
full willpower, taking into account whether somebody turns to eating when stressed. Table 4 shows the results.

[Table 4 about here]

Stress-related eating is negatively correlated with subjective well-being in the full sample, keeping body mass constant. Moreover, the marginal effects are sizeable. While the baseline probability of people reporting subjective well-being in the top category is 8.4 percent, this probability is reduced by between 1.7 and 3.7 percentage points if stress-related eating is not 'very atypical' but between 'rather atypical' and 'very typical'. However, the differential effect of obesity on subjective well-being between people with limited and full self-control does not seem to originate from stress-related eating. For the general indicator of self-control, the difference in the marginal effects of obesity on individual well-being is slightly larger when comparing people with limited and full self-control. For the specifications applying the specific indicator of self-control, the difference in marginal effects is slightly lower. However, people who lack the willpower to stick to a healthy diet still report a significantly lower subjective well-being when they are obese (marginal effect $=-1.9$ percentage points). There is no such negative effect for people who report full self-control. The corresponding coefficients and marginal probabilities are significantly different at the 5\% level across the two selfcontrol groups for both indicators when employing a simple t-Test.

The general result also holds for the specific indicator of self-control when we apply two stage least squares to estimate the partial correlation between an indicator for obesity and subjective well-being (the corresponding results can be found in the online Appendix). ${ }^{4}$ Here, we use height as an instrument while controlling for age, sex and income (as proposed by Katsaiti 2012). In the same vein, the results for the specific indicator of self-control are

\footnotetext{
${ }^{4}$ The online Appendix also includes OLS estimations as well as ordered probit estimations in order to facilitate comparisons.
} 
similar when applying Lewbel's (2012) complementary IV approach. Specific tests for reverse causation, therefore, cannot explain the reduced well-being of obese people in the case of limited self-control.

\section{Concluding Remarks}

Obesity has become a world pandemic or, to say the least, a major health issue in most western countries ( $\mathrm{Ng}$ et al. 2014; World Health Organization 2013). There is now a big debate about whether people should be "free to choose obesity" and about the role government should play in people's food consumption. Policy proposals range from doing nothing to extending nutrition labels, taxing fatty products, restricting the advertising of fastfood restaurants on television and limiting the availability of junk food in schools (for empirical analyses, see, e.g., Anderson and Butcher 2006; Chou et al. 2008; Variyam and Cawley 2006). Key to a fruitful discourse is an adequate understanding of the causes of obesity. This has spurred tremendous research in many sciences. Research in economics has provided a large number of insights on how technological progress, and the concomitant reduction in the relative price of food, has contributed to the increase in obesity. However, any analysis that is only based on the revealed preference approach is not well equipped to study whether certain behavior in fact reflects people's long-term preferences. The increased availability of food might well have overstrained people's willpower and led to suboptimal consumption decisions relative to their own standards.

In this paper, we propose specific empirical strategies in order to explore the role of limited willpower in obesity and present the respective evidence. We highlight the potential insights that we have drawn from our empirical studies of people's ex post evaluations of their consumption choices in terms of reported subjective well-being (for similar applications see Benesch et al. 2010; Gruber and Mullainathan 2005; Odermatt and Stutzer 2014). In a large 
representative sample for Swiss adults, we find that people who have limited willpower in pursuing a healthy diet suffer reduced subjective well-being when they are obese. In contrast, we observe no such reduction in well-being for people who are in control of their diet. These findings support the view that the increased availability of food and drinks makes life harder for people who are prone to jeopardize their consumption objectives when tempted.

Of course, some people actively protect themselves against temptation, e.g., by not going shopping on an empty stomach or by not having food next to them on the front seat of their car. One might argue that the people who suffer a greater utility loss owing to obesity are more likely to control their behavior. For example, obese women seem to suffer salary and promotion penalties to a greater extent than obese men (see, e.g., Baum and Ford 2004, Finkelstein et al. 2005). Women thus have a strong incentive to control their body weight. Consistent with this reasoning, people with a higher education or income level are more likely to view themselves as overweight, and make an effort to keep their BMI level constant (Oswald and Powdthavee 2007).

Even so, more and more evidence suggests that this is not enough and that there is a need for institutional innovations to help people with self-control problems to protect themselves. Importantly, these innovations should not incur high costs on those people who do not have food consumption problems. Finally, our finding supports the current appeal in the social sciences to learn more about heterogeneity in individuals' sources of self-control. 
Table 1. Covariates of Low and High BMI in Switzerland, 2002

Dependent variable: weight category

\begin{tabular}{|c|c|c|c|c|c|c|c|c|c|}
\hline & \multicolumn{9}{|c|}{$\begin{array}{l}\text { Estimated relative risk ratios, base outcome is 'normal weight' } \\
\text { (multinomial logit regression) }\end{array}$} \\
\hline & \multicolumn{3}{|c|}{ Underweight } & \multicolumn{3}{|c|}{ Overweight } & \multicolumn{3}{|c|}{ Obese } \\
\hline & RRR & & z-value & RRR & & z-value & RRR & & z-value \\
\hline \multicolumn{10}{|l|}{ Demographic factors } \\
\hline Age $15-19$ & 2.714 & $* *$ & 4.58 & 0.260 & $* *$ & -7.67 & 0.113 & $* *$ & -5.33 \\
\hline Age $20-24$ & 1.406 & $(*)$ & 1.68 & 0.582 & $* *$ & -4.27 & 0.700 & & -1.66 \\
\hline Age 25-29 & 1.277 & & 1.38 & 0.852 & $(*)$ & -1.69 & 0.888 & & -0.68 \\
\hline Age $30-34$ & 1.179 & & 1.04 & 0.965 & & -0.47 & 0.826 & & -1.28 \\
\hline Age 35-39 & \multicolumn{9}{|c|}{ Reference group } \\
\hline Age $40-44$ & 0.956 & & -0.26 & 1.206 & $*$ & 2.54 & 1.473 & $* *$ & 2.94 \\
\hline Age 45-49 & 0.936 & & -0.36 & 1.350 & $* *$ & 3.87 & 2.172 & $* *$ & 5.99 \\
\hline Age 50-54 & 0.801 & & -1.12 & 1.779 & $* *$ & 7.43 & 2.411 & $* *$ & 6.70 \\
\hline Age 55-59 & 0.660 & $*$ & -2.01 & 1.876 & $* *$ & 8.26 & 2.907 & $* *$ & 8.52 \\
\hline Age 60-64 & 0.476 & $* *$ & -2.99 & 1.983 & $* *$ & 8.62 & 2.041 & $* *$ & 5.21 \\
\hline Age 65-69 & 0.689 & & -1.18 & 2.437 & $* *$ & 8.10 & 2.686 & $* *$ & 5.64 \\
\hline Age $70-74$ & 0.642 & & -1.27 & 2.288 & $* *$ & 6.93 & 2.653 & $* *$ & 5.24 \\
\hline Age $75-79$ & 0.980 & & -0.06 & 2.345 & $* *$ & 6.76 & 2.280 & $* *$ & 4.17 \\
\hline Age 80 and older & 1.318 & & 0.82 & 1.429 & $* *$ & 2.67 & 1.228 & & 0.95 \\
\hline Female & 3.556 & $* *$ & 11.82 & 0.455 & $* *$ & -18.86 & 0.556 & $* *$ & -8.81 \\
\hline \multicolumn{10}{|l|}{ Level of education } \\
\hline Mandatory schooling & \multicolumn{9}{|c|}{ Reference group } \\
\hline Secondary general edu. & 1.209 & & 1.11 & 0.517 & $* *$ & -7.19 & 0.411 & $* *$ & -5.83 \\
\hline Secondary prof. education & 1.098 & & 0.77 & 0.761 & $* *$ & -5.26 & 0.631 & $* *$ & -6.06 \\
\hline Tertiary professional edu. & 1.280 & & 1.27 & 0.766 & $* *$ & -3.62 & 0.476 & $* *$ & -5.99 \\
\hline University & 1.524 & $*$ & 2.30 & 0.404 & $* *$ & -10.39 & 0.277 & $* *$ & -8.23 \\
\hline \multicolumn{10}{|l|}{ Marital status } \\
\hline Married & \multicolumn{9}{|c|}{ Reference group } \\
\hline Single & 1.526 & $* *$ & 3.66 & 0.730 & $* *$ & -6.21 & 1.031 & & 0.38 \\
\hline Widowed & 1.099 & & 0.53 & 0.979 & & -0.32 & 1.204 & $(*)$ & 1.87 \\
\hline Divorced & 1.309 & $(*)$ & 1.74 & 0.889 & $(*)$ & -1.89 & 0.997 & & -0.03 \\
\hline Separated & 0.824 & & -0.49 & 0.743 & $*$ & -2.07 & 1.291 & & 1.27 \\
\hline \multicolumn{10}{|l|}{ Citizenship status } \\
\hline Foreigner & 0.785 & $(*)$ & -1.84 & 1.235 & $* *$ & 3.97 & 1.114 & & 1.24 \\
\hline \multicolumn{10}{|l|}{ Main life circumstances } \\
\hline Full-time job & \multicolumn{9}{|c|}{ Reference group } \\
\hline Part-time job & 1.105 & & 1.01 & 0.724 & $* *$ & -6.33 & 0.711 & $* *$ & -4.04 \\
\hline Family business & 1.390 & & 0.72 & 0.847 & & -0.66 & 1.075 & & 0.18 \\
\hline In education & 1.356 & & -0.51 & 0.848 & $*$ & -2.51 & 0.890 & & -1.46 \\
\hline Unemployed & 0.917 & $(*)$ & 1.94 & 0.683 & & -0.78 & 0.645 & & 0.58 \\
\hline Housework & 1.631 & $(*)$ & 1.86 & 0.902 & $* *$ & -2.76 & 1.125 & $(*)$ & 1.72 \\
\hline Retired & 1.241 & & 0.84 & 0.857 & & -1.01 & 1.163 & & 0.73 \\
\hline Chronically ill & 1.273 & $* *$ & 3.22 & 0.905 & & -0.93 & 1.116 & $* *$ & 4.68 \\
\hline \multicolumn{10}{|l|}{ Income } \\
\hline Ln(equivalence income) & 0.860 & & -1.77 & 0.847 & $* *$ & -4.27 & 0.762 & $* *$ & -4.75 \\
\hline $\begin{array}{l}\text { No. of obs. } \\
\text { Pseudo } R^{2}\end{array}$ & $\begin{array}{r}19435 \\
0.076\end{array}$ & & & & & & & & \\
\hline
\end{tabular}

Notes: Multinomial logit regression. Further control variables not shown are 'education not defined', 'other paid activity', 'other life circumstances', 'income not available'. Significance levels: $\left(^{*}\right) .05<\mathrm{p}<.1,{ }^{*} .01<\mathrm{p}<.05, * *$ $\mathrm{p}<.01$.

Data source: Swiss Health Survey 2002. 
Table 2. Effects of Reported Ignorance and Willpower Towards Health and Nutrition on BMI

Dependent variable: weight category

\begin{tabular}{|c|c|c|c|c|c|c|c|c|}
\hline & \multicolumn{8}{|c|}{$\begin{array}{l}\text { Estimated relative risk ratios, base outcome is 'normal weight' } \\
\text { (multinomial logit regression) }\end{array}$} \\
\hline & \multicolumn{3}{|c|}{ Underweight } & \multicolumn{2}{|c|}{ Overweight } & \multicolumn{3}{|c|}{ Obese } \\
\hline & RRR & & z-value & RRR & z-value & RRR & & z-value \\
\hline \multicolumn{9}{|c|}{ Estimation A - Importance of health in one's life } \\
\hline Covariates of BMI & \multicolumn{8}{|c|}{ Included } \\
\hline Health is not important & 1.614 & $* *$ & 3.68 & $1.300 * *$ & 4.12 & 1.513 & $* *$ & 4.18 \\
\hline Health is relevant & \multicolumn{8}{|c|}{ Reference group } \\
\hline Health is very important & 1.151 & & 1.29 & 0.980 & -0.41 & 0.898 & & -1.39 \\
\hline No. of obs. & 15504 & & & & & & & \\
\hline Pseudo $\mathrm{R}^{2}$ & 0.079 & & & & & & & \\
\hline \multicolumn{9}{|c|}{ Estimation B - Caring about nutrition } \\
\hline Covariates of BMI & \multirow{2}{*}{\multicolumn{8}{|c|}{$\begin{array}{c}\text { Included } \\
\text { Reference group }\end{array}$}} \\
\hline Does not care & & & & & & & & \\
\hline Does care & 0.737 & $* *$ & -3.61 & $0.931 \quad(*)$ & -1.84 & 0.811 & $* *$ & -3.44 \\
\hline No. of obs. & 19420 & & & & & & & \\
\hline Pseudo $\mathrm{R}^{2}$ & 0.077 & & & & & & & \\
\hline \multicolumn{9}{|c|}{ Estimation $\mathrm{C}$ - Obstacles to a healthy diet } \\
\hline Covariates of BMI & \multicolumn{8}{|c|}{ Included } \\
\hline Time-consuming & 1.191 & $(*)$ & 1.83 & 0.966 & -0.77 & 0.946 & & -0.76 \\
\hline $\begin{array}{l}\text { Not enough choice in } \\
\text { shops }\end{array}$ & 0.991 & & -0.06 & 1.028 & 0.38 & 1.240 & $(*)$ & 1.91 \\
\hline $\begin{array}{l}\text { Not enough choice in } \\
\text { restaurants and canteens }\end{array}$ & 1.120 & & 1.15 & 0.943 & -1.26 & 0.883 & & -1.60 \\
\hline $\begin{array}{l}\text { Healthy food is relatively } \\
\text { expensive }\end{array}$ & 0.879 & & -1.37 & 1.016 & 0.39 & 1.195 & $* *$ & 2.64 \\
\hline $\begin{array}{l}\text { Not enough support from } \\
\text { others }\end{array}$ & 0.822 & & -1.17 & 1.111 & 1.40 & 1.246 & $(*)$ & 1.92 \\
\hline Others put me off & 0.855 & & -0.57 & 0.905 & -0.89 & 0.950 & & -0.29 \\
\hline $\begin{array}{l}\text { Marked preference for } \\
\text { quality of food }\end{array}$ & 0.726 & $* *$ & -3.06 & $1.470 * *$ & 9.20 & 1.853 & $* *$ & 9.18 \\
\hline $\begin{array}{l}\text { Marked preference for } \\
\text { quantity of food }\end{array}$ & 0.816 & & -1.39 & $1.189 * *$ & 3.00 & 1.178 & $(*)$ & 1.79 \\
\hline $\begin{array}{l}\text { Everyday habits and } \\
\text { necessities }\end{array}$ & 0.898 & & -1.11 & 1.019 & 0.44 & 1.094 & & 1.26 \\
\hline Lack of willpower & 0.931 & & -0.64 & $1.100 \quad(*)$ & 1.90 & 1.402 & $* *$ & 4.36 \\
\hline No. of obs. & 14202 & & & & & & & \\
\hline Pseudo $\mathrm{R}^{2}$ & 0.089 & & & & & & & \\
\hline \multicolumn{9}{|l|}{ Estimation D - Mastery } \\
\hline Covariates of BMI & \multirow{2}{*}{\multicolumn{8}{|c|}{$\begin{array}{l}\text { Included } \\
\text { Reference group }\end{array}$}} \\
\hline Limited self-control & & & & & & & & \\
\hline Full self-control & 0.961 & & -0.35 & 0.972 & -0.61 & 0.949 & & -0.69 \\
\hline No. of obs. & 14516 & & & & & & & \\
\hline Pseudo $\mathrm{R}^{2}$ & 0.079 & & & & & & & \\
\hline
\end{tabular}

Notes: Multinomial logit regression. Same control variables included as in Table 1. Significance levels: $(*)$ $.05<\mathrm{p}<.1, * .01<\mathrm{p}<.05, * * \mathrm{p}<.01$.

Data source: Swiss Health Survey 2002. 
Table 3. BMI and Reported Subjective Well-Being

Dependent variable: subjective well-being [1-6]

\begin{tabular}{|c|c|c|c|c|c|}
\hline & \multirow[t]{2}{*}{ Full sample } & \multicolumn{2}{|c|}{$\begin{array}{c}\text { General indicator of self-control: } \\
\text { Mastery }\end{array}$} & \multicolumn{2}{|c|}{$\begin{array}{c}\text { Specific indicator of self-control } \\
\text { Lack of willpower is an obstacle } \\
\text { to a healthy diet }\end{array}$} \\
\hline & & $\begin{array}{l}\text { limited } \\
\text { self-control }\end{array}$ & $\begin{array}{c}\text { full } \\
\text { self-control }\end{array}$ & $\begin{array}{l}\text { limited } \\
\text { self-control }\end{array}$ & $\begin{array}{c}\text { full } \\
\text { self-control }\end{array}$ \\
\hline & \multicolumn{5}{|c|}{ Marginal effects for the top category of SWB (ordered probit regressions) } \\
\hline Specification A & & & & & \\
\hline Underweight & $\begin{array}{l}-0.023 \\
(6.59 \mathrm{e}-3)\end{array}$ & 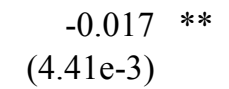 & $\begin{array}{r}-0.013 \\
(3.11 \mathrm{e}-2)\end{array}$ & $\begin{array}{r}-0.016 \\
(1.27 \mathrm{e}-2)\end{array}$ & $\begin{array}{r}-0.018 \\
(8.20 \mathrm{e}-3)\end{array}$ \\
\hline Normal weight & & \multicolumn{2}{|c|}{ Reference group } & & \\
\hline Overweight & $\begin{array}{r}-0.002 \\
(3.41 \mathrm{e}-3)\end{array}$ & $\begin{array}{r}-0.001 \\
(2.63 e-3)\end{array}$ & $\begin{array}{r}-0.022 \quad(*) \\
(1.24 \mathrm{e}-2)\end{array}$ & $\begin{array}{r}-0.009 \\
(6.40 \mathrm{e}-3)\end{array}$ & $\begin{array}{r}-0.001 \\
(4.13 \mathrm{e}-3)\end{array}$ \\
\hline Obese & $\begin{array}{l}-0.013 \\
(5.16 \mathrm{e}-3)\end{array}$ & $\begin{array}{l}-0.011 \\
(3.77 \mathrm{e}-3)\end{array}$ & $\begin{array}{r}-0.007 \\
(2.06 \mathrm{e}-2)\end{array}$ & $\begin{array}{l}-0.033 \\
(7.63 \mathrm{e}-3)\end{array}$ & $\begin{array}{r}-0.001 \\
(6.83 \mathrm{e}-3)\end{array}$ \\
\hline Control variables & & \multicolumn{2}{|c|}{ Age categories and sex included } & & \\
\hline Baseline prob. & 0.099 & 0.055 & 0.230 & 0.086 & 0.097 \\
\hline No. of obs. & 15108 & 10681 & 3392 & 3458 & 10117 \\
\hline Pseudo $\mathrm{R}^{2}$ & 0.002 & 0.002 & 0.004 & 0.003 & 0.002 \\
\hline \multicolumn{6}{|l|}{ Specification B } \\
\hline Underweight & $\begin{array}{l}-0.016 * \\
(6.57 \mathrm{e}-3)\end{array}$ & $\begin{array}{rl}-0.012 & * * \\
(4.42 \mathrm{e}-3) & \end{array}$ & $\begin{array}{r}-0.016 \\
(3.06 \mathrm{e}-2)\end{array}$ & $\begin{array}{r}-0.009 \\
(1.28 \mathrm{e}-2)\end{array}$ & $\begin{array}{r}-0.012 \\
(8.18 \mathrm{e}-3)\end{array}$ \\
\hline Normal weight & \multicolumn{5}{|c|}{ Reference group } \\
\hline Overweight & $\begin{array}{r}-0.003 \\
(3.27 \mathrm{e}-3)\end{array}$ & $\begin{array}{r}-0.002 \\
(2.46 \mathrm{e}-3)\end{array}$ & $\begin{array}{r}-0.016 \\
(1.24 \mathrm{e}-2)\end{array}$ & $\begin{array}{r}-0.009 \\
(6.01 \mathrm{e}-3)\end{array}$ & $\begin{array}{r}-0.001 \\
(3.96 \mathrm{e}-3)\end{array}$ \\
\hline Obese & $\begin{array}{r}-0.007 \\
(5.16 \mathrm{e}-3)\end{array}$ & $\begin{array}{l}-0.008 * \\
(3.69 \mathrm{e}-3)\end{array}$ & $\begin{array}{r}0.009 \\
(2.12 \mathrm{e}-2)\end{array}$ & $\begin{array}{l}-0.026 \\
(7.51 \mathrm{e}-3)\end{array}$ & $\begin{array}{r}0.005 \\
(6.86 \mathrm{e}-3)\end{array}$ \\
\hline Control variables & \multicolumn{5}{|c|}{$\begin{array}{l}\text { All factors included } \\
\text { (see Appendix A.2) }\end{array}$} \\
\hline Baseline prob. & 0.092 & 0.050 & 0.225 & 0.078 & 0.090 \\
\hline No. of obs. & 15108 & 10681 & 3392 & 3458 & 10117 \\
\hline Pseudo $\mathrm{R}^{2}$ & 0.021 & 0.021 & 0.019 & 0.027 & 0.021 \\
\hline
\end{tabular}

Notes: Marginal effects based on ordered probit regressions. Specifications A and B differ in terms of control variables. Standard errors in parentheses. Significance levels: $(*) .05<\mathrm{p}<.1,{ }^{*} .01<\mathrm{p}<.05, * * \mathrm{p}<.01$.

Data source: Swiss Health Survey 2002. 
Table 4. Reverse Causality: Stress-related Eating

Dependent variable: subjective well-being [1-6]

\begin{tabular}{|c|c|c|c|c|c|c|c|}
\hline & \multicolumn{2}{|c|}{ Full sample } & \multicolumn{2}{|c|}{$\begin{array}{c}\text { General indicator of self-control: } \\
\text { Mastery }\end{array}$} & \multicolumn{3}{|c|}{$\begin{array}{c}\text { Specific indicator of self-control: } \\
\text { Lack of willpower is an obstacle } \\
\text { to a healthy diet }\end{array}$} \\
\hline & & & $\begin{array}{c}\text { limited } \\
\text { self-control }\end{array}$ & $\begin{array}{c}\text { full } \\
\text { self-control }\end{array}$ & $\begin{array}{c}\text { limited } \\
\text { self-control }\end{array}$ & \multicolumn{2}{|c|}{$\begin{array}{c}\text { full } \\
\text { self-control }\end{array}$} \\
\hline & \multicolumn{7}{|c|}{ Marginal effects for the top category of SWB (ordered probit regressions) } \\
\hline Underweight & $\begin{array}{r}-0.013 \\
(6.54 \mathrm{e}-3)\end{array}$ & $(*)$ & $\begin{array}{r}-0.102 * \\
(4.52 \mathrm{e}-3)\end{array}$ & $\begin{array}{r}0.002 \\
(3.26 \mathrm{e}-2)\end{array}$ & $\begin{array}{r}-0.007 \\
(1.33 \mathrm{e}-2)\end{array}$ & $\begin{array}{r}-0.010 \\
(7.83 e-3)\end{array}$ & \\
\hline Normal weight & & & Refere & group & & & \\
\hline Overweight & $\begin{array}{r}-0.001 \\
(3.29 \mathrm{e}-3)\end{array}$ & & $\begin{array}{r}-0.000 \\
(2.49 \mathrm{e}-3)\end{array}$ & $\begin{array}{r}-0.013 \\
(1.31 \mathrm{e}-2)\end{array}$ & $\begin{array}{r}-0.002 \\
(6.33 \mathrm{e}-3)\end{array}$ & $\begin{array}{r}-0.000 \\
(3.91 \mathrm{e}-3)\end{array}$ & \\
\hline Obese & $\begin{array}{r}-0.003 \\
(5.33 \mathrm{e}-3)\end{array}$ & & $\begin{array}{r}-0.007 \quad(*) \\
(3.78 \mathrm{e}-3)\end{array}$ & $\begin{array}{r}0.017 \\
(2.31 \mathrm{e}-2)\end{array}$ & $\begin{array}{r}-0.019 * \\
(8.26 \mathrm{e}-3)\end{array}$ & $\begin{array}{r}0.009 \\
(7.02 \mathrm{e}-3)\end{array}$ & \\
\hline $\begin{array}{l}\text { Stress-related } \\
\text { eating } \\
\text { - very atypical }\end{array}$ & & & Refere & e group & & & \\
\hline - rather atypical & $\begin{array}{r}-0.025 \\
(3.16 \mathrm{e}-3)\end{array}$ & & $\begin{array}{r}-0.006 * \\
(2.53 \mathrm{e}-3)\end{array}$ & $\begin{array}{r}-0.074 * * \\
(1.32 \mathrm{e}-2)\end{array}$ & $\begin{array}{r}-0.022 \\
(6.07 \mathrm{e}-3)\end{array}$ & $\begin{array}{r}-0.022 \\
(3.79 \mathrm{e}-3)\end{array}$ & \\
\hline - part-part & $\begin{array}{r}-0.017 \\
(3.54 \mathrm{e}-3)\end{array}$ & $* *$ & $\begin{aligned}-0.005 \quad(*) \\
(2.81 \mathrm{e}-3)\end{aligned}$ & $\begin{array}{r}-0.029 \quad(*) \\
(1.58 \mathrm{e}-2)\end{array}$ & $\begin{array}{r}-0.014 \\
(6.85 \mathrm{e}-3)\end{array}$ & $\begin{array}{r}-0.015 \\
(4.23 e-3)\end{array}$ & \\
\hline - rather typical & $\begin{array}{r}-0.037 \\
(3.58 \mathrm{e}-3)\end{array}$ & $* *$ & $\begin{array}{r}-0.015 * * \\
(2.88 \mathrm{e}-3)\end{array}$ & $\begin{array}{r}-0.062 \\
(2.08 \mathrm{e}-2)\end{array}$ & $\begin{array}{r}-0.033 * * \\
(6.67 \mathrm{e}-3)\end{array}$ & $\begin{array}{r}-0.034 \\
(4.38 \mathrm{e}-3)\end{array}$ & \\
\hline - very typical & $\begin{array}{r}-0.018 \\
(5.79 \mathrm{e}-3)\end{array}$ & $* *$ & $\begin{array}{r}-0.011 * \\
(4.25 \mathrm{e}-3)\end{array}$ & $\begin{array}{r}0.048 \\
(3.35 \mathrm{e}-2)\end{array}$ & $\begin{array}{r}-0.022 * \\
(9.56 \mathrm{e}-3)\end{array}$ & $\begin{array}{r}-0.006 \\
(7.95 \mathrm{e}-3)\end{array}$ & \\
\hline Control variables & & & $\begin{array}{l}\text { All fact } \\
\text { (see Ap }\end{array}$ & $\begin{array}{l}\text { included } \\
\text { ndix A.2) }\end{array}$ & & & \\
\hline Baseline prob. & 0.084 & & 0.048 & 0.216 & 0.076 & 0.081 & \\
\hline No. of obs. & 13699 & & 10082 & 2991 & 3291 & 9141 & \\
\hline Pseudo $\mathrm{R}^{2}$ & 0.024 & & 0.022 & 0.022 & 0.030 & 0.024 & \\
\hline
\end{tabular}

Notes: Marginal effects based on ordered probit regressions. Standard errors in parentheses. Significance levels: (*) $.05<\mathrm{p}<.1, * .01<\mathrm{p}<.05, * * \mathrm{p}<.01$.

Data source: Swiss Health Survey 2002. 


\section{Appendix}

\section{Information About the Questionnaire:}

The Swiss Health Survey combines responses from a telephone survey and a questionnaire mailed going to the same individuals. The sampling population was the resident population of Switzerland aged 15 and over. In total, 19,706 individuals were interviewed, and 16,141 of them responded to a supplementary written questionnaire. For 19,471 respondents, there is complete information about their body mass.

\section{Relevant Questions:}

Subjective well-being (translated from Grob et al. 1991)

To what extent do the following statements apply to you?

- My future looks bright.

- I enjoy life more than most people.

- I am satisfied with how my life plans materialize.

- I deal well with those things in my life that cannot be changed.

- Whatever happens, I make the best out of it.

- I enjoy my life.

- My life is meaningful to me.

- My life is on the right track.

Possible answers: 1=completely wrong, 2=very wrong, 3=rather wrong, 4=rather accurate, $5=$ very accurate, $6=$ completely accurate.

The responses are added together (SWB_tot) and summarized using a six-point scale according to the following criteria:

SWB_tot $>=44 \&$ SWB_tot $<=48 \prod \mathrm{SWB}=6$

SWB_tot $>=40 \&$ SWB_tot $<44 \prod \mathrm{SWB}=5$

SWB_tot $>=36 \& S W B \_$tot $<40 \prod S W B=4$

SWB_tot $>=32 \& S W B \_$tot $<36 \prod \mathrm{SWB}=3$

SWB_tot $>=28 \& \mathrm{SWB}$-tot $<32 \prod \mathrm{SWB}=2$

SWB_tot $>=8 \&$ SWB_tot $<28 \prod \mathrm{SWB}=1$

Mastery (based on 4 out of 7 questions from Pearlin et al. 1981)

When you think about your life, how strongly do you agree or disagree with these statements about yourself?

- There is really no way I can solve some of the problems I have.

- Sometimes I feel that I'm being pushed around in life.

- I have little control over the things that happen to me.

- I often feel helpless in dealing with the problems of life.

Possible responses: completely agree $(=1)$, rather agree $(=2)$, rather disagree $(=3)$, completely $(=4)$ disagree. Thus, the raw indicator for mastery takes the values 4 to 16 , whereby 16 is taken as full self-control and lower values as limited self-control.

\section{Importance of health in one's life}

How important is health for you? To what extent do the following statements apply to you?

Please tick the statement that fits you best!

- I live without caring about potential consequences for my health.

- Thoughts about preserving my health affect my lifestyle.

- Health considerations largely determine how I live. 


\section{Caring about nutrition}

Do you care about certain things in your diet?

- No, I don't.

- Yes, I do.

\section{Obstacles to a healthy diet}

Many people - maybe you too - attach importance to a healthy diet. Do you see any obstacles for someone pursuing a healthy diet? Please tick all the reasons that apply!

- Too much time spent on shopping and preparing food

- Not enough choice in shops

- Not enough choice in restaurants and canteens

- Healthy food is relatively expensive

- Not enough support from others

- Others put me off

- Strong preference for quality of food

- Strong preference for quantity of food

- Habits and necessities of everyday life

- Lack of willpower, lack of belief in success

\section{Stress-related eating}

In the following, a description is given how people can react to various difficult, stressful and annoying situations. Please tick what you typically do when you are stressed.

'I eat something.'

- very atypical

- rather atypical

- part-part

- rather typical

- very typical 
Table A.1. Descriptive Statistics

\begin{tabular}{|c|c|c|c|c|c|}
\hline & $\begin{array}{l}\text { Mean / } \\
\text { fraction }\end{array}$ & Std. dev. & & $\begin{array}{l}\text { Mean / } \\
\text { fraction }\end{array}$ & Std. dev. \\
\hline Subjective well-being & 3.76 & 1.309 & Household composition & & \\
\hline SWB 1 & $4.94 \%$ & & 1 adult & $28.01 \%$ & \\
\hline SWB 2 & $11.81 \%$ & & 2 adults & $53.75 \%$ & \\
\hline SWB 3 & $25.62 \%$ & & 3 adults & $10.58 \%$ & \\
\hline SWB 4 & $27.61 \%$ & & 4 adults and more & $7.65 \%$ & \\
\hline SWB 5 & $20.07 \%$ & & No children & $72.86 \%$ & \\
\hline SWB 6 & $9.96 \%$ & & 1 child & $10.90 \%$ & \\
\hline BMI & 24.24 & 4.176 & 2 children & $12.05 \%$ & \\
\hline Underweight & $3.77 \%$ & & 3 children and more & $4.19 \%$ & \\
\hline Normal weight & $59.18 \%$ & & Citizenship status & & \\
\hline Overweight & $29.26 \%$ & & National & $90.14 \%$ & \\
\hline Obese & $7.86 \%$ & & Foreigner & $9.86 \%$ & \\
\hline Demographic factors & & & Main life circumstances & $39.20 \%$ & \\
\hline Age & 47.81 & 17.044 & Full-time job & $21.20 \%$ & \\
\hline Male & $45.26 \%$ & & Part-time job & $0.54 \%$ & \\
\hline Female & $54.74 \%$ & & Family business & $0.48 \%$ & \\
\hline Level of education & & & In education & $4.76 \%$ & \\
\hline Mandatory schooling & $14.79 \%$ & & Unemployed & $1.70 \%$ & \\
\hline Secondary general edu. & $6.08 \%$ & & Housework & $20.32 \%$ & \\
\hline Secondary prof. edu. & $58.46 \%$ & & Retired & $17.53 \%$ & \\
\hline Tertiary professional edu. & $10.46 \%$ & & Chronically ill & $2.28 \%$ & \\
\hline University & $7.31 \%$ & & Other & $1.36 \%$ & \\
\hline Marital status & & & Income & & \\
\hline Married & $55.62 \%$ & & Ln(equivalence income) & 8.23 & 0.50 \\
\hline Single & $26.30 \%$ & & & & \\
\hline Widowed & $7.86 \%$ & & & & \\
\hline Divorced & $8.77 \%$ & & & & \\
\hline Separated & $1.45 \%$ & & & & \\
\hline
\end{tabular}

Notes: Descriptive statistics are for the sample underlying the estimation in Table A.2 based on 15,108 observations. Mean income is calculated based on 14,160 observations.

Data source: Swiss Health Survey 2002. 
Table A.2. Covariates of Subjective Well-Being in Switzerland, 2002

Dependent variable: subjective well-being [1-6]

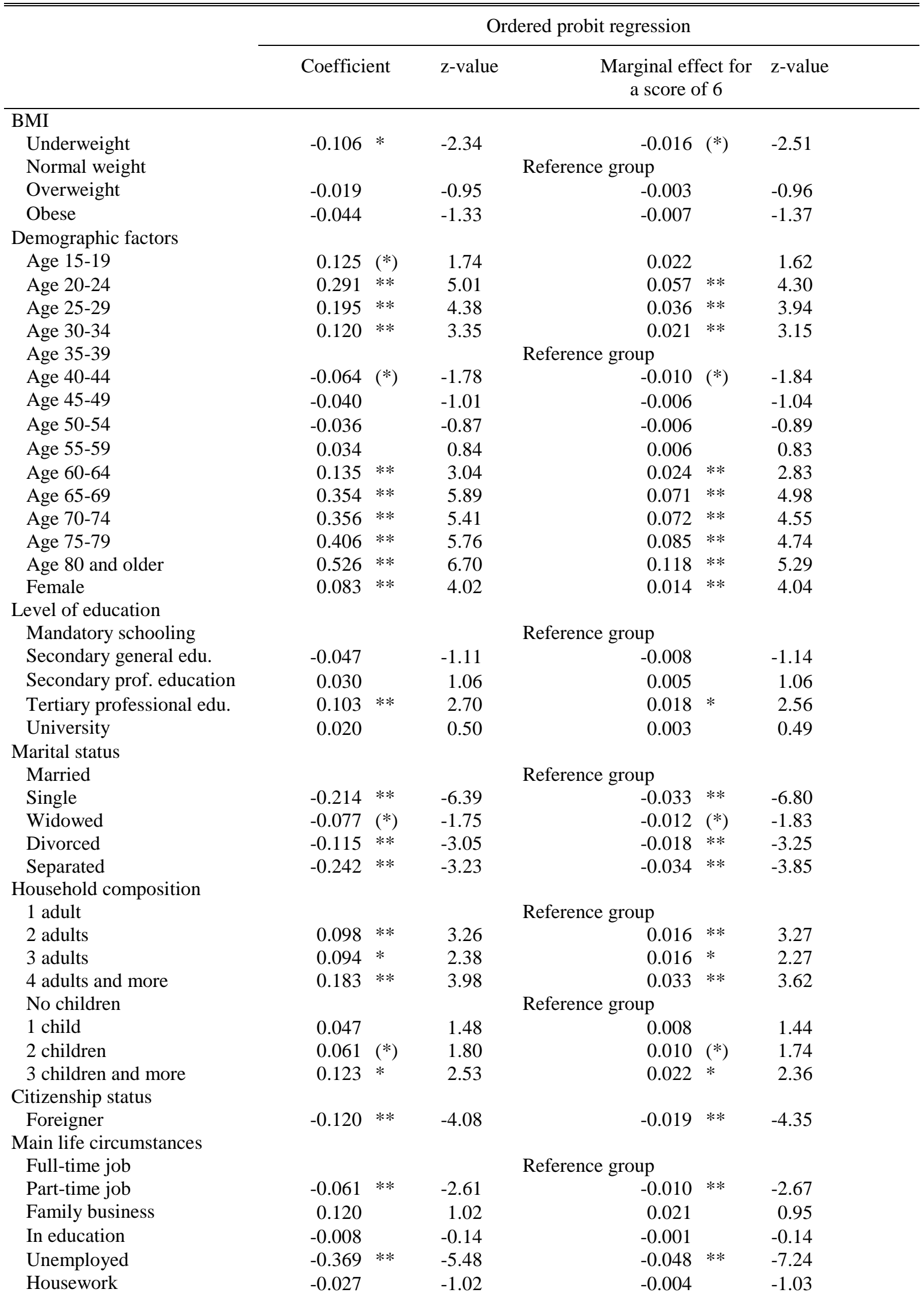




\begin{tabular}{lccccc} 
Retired & -0.183 & $* *$ & -3.48 & $-0.028 * *$ & -3.77 \\
$\quad$ Chronically ill & -0.578 & $* *$ & -9.23 & $-0.065 * *$ & -14.41 \\
Income & & & & & \\
$\quad$ Ln(equivalence income) & 1.411 & $* *$ & 8.70 & & \\
\hline No. of obs. & 15108 & & & \\
Pseudo R & 0.021 & & & \\
\hline \hline
\end{tabular}

Notes: Ordered probit regression. Further control variables not shown are 'education not defined', 'other paid activity', 'other life circumstances', 'income not available', 'interview in French', 'interview in Italian'. Significance levels: $(*) .05<\mathrm{p}<.1, * .01<\mathrm{p}<.05, * * \mathrm{p}<.01$.

Data source: Swiss Health Survey 2002. 
Table A.3. Distribution of Observations

\begin{tabular}{|c|c|c|c|c|c|}
\hline & Underweight & $\begin{array}{l}\text { Normal } \\
\text { weight }\end{array}$ & Overweight & Obese & Total \\
\hline \multicolumn{6}{|l|}{ Mastery } \\
\hline Limited self-control & $\begin{array}{c}436 \\
(3.10 \%)\end{array}$ & $\begin{array}{c}6,476 \\
(46.02 \%)\end{array}$ & $\begin{array}{c}2,977 \\
(21.15 \%)\end{array}$ & $\begin{array}{c}792 \\
(5.63 \%)\end{array}$ & $\begin{array}{c}10,681 \\
(75.90 \%)\end{array}$ \\
\hline Full self-control & $\begin{array}{c}109 \\
(0.77 \%)\end{array}$ & $\begin{array}{c}1,935 \\
(13.75 \%)\end{array}$ & $\begin{array}{c}1,072 \\
(7.62 \%)\end{array}$ & $\begin{array}{c}276 \\
(1.96 \%)\end{array}$ & $\begin{array}{c}3,392 \\
(24.10 \%)\end{array}$ \\
\hline Total & $\begin{array}{c}545 \\
(3.87 \%)\end{array}$ & $\begin{array}{c}8,411 \\
(59.77 \%)\end{array}$ & $\begin{array}{c}4,049 \\
(28.77 \%)\end{array}$ & $\begin{array}{c}1,068 \\
(7.59 \%)\end{array}$ & $\begin{array}{c}14,073 \\
(100.00 \%)\end{array}$ \\
\hline \multicolumn{6}{|l|}{ Pearson $\chi_{3}^{2}=24.78^{* *}$} \\
\hline \multicolumn{6}{|c|}{ Willpower in sticking to a healthy diet } \\
\hline Limited self-control & $\begin{array}{c}133 \\
(0.98 \%)\end{array}$ & $\begin{array}{c}2,035 \\
(14.99 \%)\end{array}$ & $\begin{array}{c}975 \\
(7.18 \%)\end{array}$ & $\begin{array}{c}315 \\
(2.32 \%)\end{array}$ & $\begin{array}{c}3,458 \\
(25.47 \%)\end{array}$ \\
\hline Full self-control & $\begin{array}{c}384 \\
(2.83 \%)\end{array}$ & $\begin{array}{c}5,961 \\
(43.91 \%)\end{array}$ & $\begin{array}{c}3,000 \\
(22.10 \%)\end{array}$ & $\begin{array}{c}772 \\
(5.69 \%)\end{array}$ & $\begin{array}{c}10,117 \\
(74.53 \%)\end{array}$ \\
\hline Total & $\begin{array}{c}517 \\
(3.81 \%)\end{array}$ & $\begin{array}{c}7,996 \\
(58.90 \%)\end{array}$ & $\begin{array}{c}3,975 \\
(29.28 \%)\end{array}$ & $\begin{array}{c}1,087 \\
(8.01 \%)\end{array}$ & $\begin{array}{c}13,575 \\
(100.00 \%)\end{array}$ \\
\hline Pearson $\chi_{3}^{2}=8.93^{*}$ & & & & & \\
\hline
\end{tabular}

Significance levels: $\left(^{*}\right) .05<\mathrm{p}<.1, * .01<\mathrm{p}<.05, * * \mathrm{p}<.01$.

Data source: Swiss Health Survey 2002. 


\section{References}

Anderson, Patricia M. and Kristin F. Butcher (2006). Reading, Writing and Refreshments: Are School Finances Contributing to Children's Obesity? Journal of Human Resources 41(3): 467-494.

Ball, Kylie, David Crawford and Justin Kenardy (2004). Longitudinal Relationships Among Overweight, Life Satisfaction, and Aspirations in Young Women. Obesity Research 12(6): 1019-1030.

Baum, Charles L. and William F. Ford (2004). The Wage Effects of Obesity: A Longitudinal Study. Health Economics 13(9): 885-899.

Baum, Charles L. (2009). The Effects of Cigarette Costs on BMI and Obesity. Health Economics 18(1): 3-19.

Baum, Charles L. and Shin-Yi Chou (2011). The Socio-Economic Causes of Obesity. NBER Working Paper No. 17423, Cambridge, MA.

Benesch, Christine, Bruno S. Frey and Alois Stutzer (2010). TV Channels, Self-Control and Happiness. The B.E. Journal of Economic Analysis \& Policy 10(1): Article 86.

Blundell, John E. and Angela Gillett (2001). Control of Food Intake in the Obese. Obesity Research 9 (Suppl. 4): 263S-270S.

Brunello, Giorgio, Pierre-Carl Michaud and Anna Sanz-de-Galdeano (2009). The Rise of Obesity in Europe: An Economic Perspective. Economic Policy 24: 551-596.

Cavaco, Sandra, Tor Eriksson and Ali Skalli (2014). Life Cycle Development of Obesity and Its Determinants in Six European Countries. Economics \& Human Biology 14(C): 6278.Economics \& Human Biology, Volume 14, July 2014, Pages 62-78.

Cawley, John (2010). The Economics of Childhood Obesity. Health Affairs 29(3): 364-371.

Chou, Shin-Yi, Michael Grossman and Henry Saffer (2004). An Economic Analysis of Adult Obesity: Results from the Behavioral Risk Factor Surveillance System. Journal of Health Economics 23(3): 565-587.

Chou, Shin-Yi, Inas Rashad and Michael Grossman (2008). Fast-Food Restaurant Advertising on Television and Its Influence on Childhood Obesity. Journal of Law and Economics 51(4): 599-618.

Currie, Janet, Stefano DellaVigna, Enrico Moretti and Vikram Singh Pathania (2009). The Effect of Fast Food Restaurants on Obesity and Weight Gain. American Economic Journal: Economic Policy 2(3): 32-63.

Cutler, David M., Edward L. Glaeser and Jesse M. Shapiro (2003). Why Have Americans Become More Obese? Journal of Economic Perspectives 17(3): 93-118.

Di Tella, Rafael and Robert MacCulloch (2006). Some Uses of Happiness Data in Economics. The Journal of Economic Perspectives 20(1): 25-46.

Etilé, Fabrice (2007). Social Norms, Ideal Body Weight and Food Attitudes. Health Economics 16(9): 945-966.

Finkelstein, Eric A., Christopher J. Ruhm and Katherine M. Kosa (2005). Economic Causes and Consequences of Obesity. Annual Review of Public Health 26: 239-257.

Flegal, Katherine M., Barry I. Graubard, David F. Williamson and Mitchell H. Gail (2005). Excess Deaths Associated With Underweight, Overweight, and Obesity. Journal of the American Medical Association 293(15): 1861-1867.

Flegal, Katherine M., Brian K. Kit, Heather Orpana and Barry I. Graubard (2013). Association of All-Cause Mortality With Overweight and Obesity Using Standard Body Mass Index Categories: A Systematic Review and Meta-Analysis. Journal of the American Medical Association 309(1): 71-82.

Frey, Bruno S. and Alois Stutzer (2000). Happiness, Economy and Institutions. Economic Journal 110(466): 918-938. 
Frey, Bruno S. and Alois Stutzer (2012). The Use of Happiness Research for Public Policy. Social Choice and Welfare 38(4): 659-674.

Grob, Alexander, Ruth Luthi, Florian G. Kaiser and August Flammer (1991). Berner Fragebogen zum Wohlbefinden Jugendlicher (Bfw). The Bern Subjective Well-Being Questionnaire for Adolescents (Bfw). Diagnostica 37(1): 66-75.

Grossman, Michael and Naci Mocan (2011). Economic Aspects of Obesity. Chicago and London: University of Chicago Press.

Gruber, Jonathan H. and Sendhil Mullainathan (2005). Do Cigarette Taxes Make Smokers Happier? Advances in Economic Analysis and Policy 5(1): 1-43.

Gruber, Jonathan H. and Michael Frakes (2006). Does Falling Smoking Lead to Rising Obesity? Journal of Health Economics 25(2): 183-197.

Jones Putnam, Judith and Jane E. Allshouse (1999). Food Consumption, Prices, and Expenditures, 1970-97. Statistical Bulletin No. 965. Washington: U.S. Department of Agriculture.

Katsaiti, Marina-Selini (2012). Obesity and Happiness. Applied Economics 44(31): 41014114.

Korkeila, M., J. Kaprio, A. Rissanen, M. Koskenvuo and T. I. A. Sorensen (1998). Predictors of Major Weight Gain in Adult Finns: Stress, Life Satisfaction and Personality Traits. International Journal of Obesity 22(10): 949-957.

Lakdawalla, Darius and Tomas Philipson (2009). The Growth of Obesity and Technological Change. Economics and Human Biology 7(3): 283-293.

Lewbel, Arthur (2012). Using Heteroscedasticity to Identify and Estimate Mismeasured and Endogenous Regressor Models. Journal of Business and Economic Statistics 30(1): 67-80.

McElroy, Susan L., Renu Kotwal, Shishuka Malhotra, Erik B. Nelson, Paul E. Keck and Charles B. Nemeroff (2004). Are Mood Disorders and Obesity Related? A Review for the Mental Health Professional. Journal of Clinical Psychiatry 65(5): 634-651.

Muraven, Mark, Dianne M. Tice and Roy F. Baumeister (1998). Self-Control as Limited Resource: Regulatory Depletion Patterns. Journal of Personality and Social Psychology 74(3): 774-789.

Needham, Belinda L. and Robert Crosnoe (2005). Overweight Status and Depressive Symptoms During Adolescence. Journal of Adolescent Health 36(1): 48-55.

$\mathrm{Ng}$, Marie et al. (2014). Global, Regional, and National Prevalence of Overweight and Obesity in Children and Adults During 1980-2013: A Systematic Analysis for the Global Burden of Disease Study 2013. The Lancet 384(9945): 766-781.

Odermatt, Reto and Alois Stutzer (2014). Smoking Bans, Cigarette Prices and Life Satisfaction. Mimeo, University of Basel.

Offer, Avner (2001). Body Weight and Self-Control in the United States and Britain Since the 1950s. Social History of Medicine 14(1): 79-106.

Oswald, Andrew and Nattavudh Powdthavee (2007). Obesity, Unhappiness, and The Challenge of Affluence: Theory and Evidence. Economic Journal 117(523): F441F459.

Pearlin, Leonard I., Elizabeth G. Menaghan, Morton A. Lieberman and Joseph T. Mullan (1981). The Stress Process. Journal of Health and Social Behavior 22(4): 337-356.

Smith, Trenton G. (2009). Reconciling Psychology with Economics: Obesity, Behavioral Biology, and Rational Overeating. Journal of Bioeconomics 11(3): 249-282.

Smith, Trenton G. (2012). Economic Stressors and the Demand for "Fattening" Foods. American Journal of Agricultural Economics 94 (2): 324-330.

Stutzer, Alois and Bruno S. Frey (2010). Recent Advances in the Economics of Individual Subjective Well-Being. Social Research: An International Quarterly 77(2): 679-714. 
Swinburn, Boyd A., Gary Sacks, Kevin D. Hall, Klim McPherson, Diane T. Finegood, Marjory L. Moodie and Steven L. Gortmaker (2011). The Global Obesity Pandemic: Shaped by Global Drivers and Local Environments. The Lancet 378(9793): 804-814.

Tomer, John (2011). What Causes Obesity? And Why Has It Grown So Much? Challenge 54(4): 22-49.

Variyam, Jayachandran N. and John Cawley (2006). Nutrition Labels and Obesity. NBER Working Paper No. 11956, Cambridge, MA.

Wang, Youfa and May A. Beydoun (2007). The Obesity Epidemic in the United States Gender, Age, Socioeconomic, Racial/Ethnic, and Geographic Characteristics: A Systematic Review and Meta-Regression Analysis. Epidemiologic Reviews 29(1): 628.

Wang, Y. Claire, Klim McPherson, Tim Marsh, Steven L. Gortmaker and Martin Brown (2011). Health and Economic Burden of the Projected Obesity Trends in the USA and the UK. The Lancet 378(9793): 815-825.

World Health Organization (2013). Global Action Plan for the Prevention and Control of Noncommunicable Diseases (Resolution WHA66.10). Geneva: WHO Press. 